\title{
Associações comunitárias e políticas educacionais para a infância: entre relações de força e performances
}

\author{
Antonia Almeida Silva ${ }^{\mathrm{I}, \text { II }}$ \\ Faní Quitéria Nascimento Rehem ${ }^{\mathrm{III}, \mathrm{IV}}$
}

http://dx.doi.org/100.24109/2176-6681.rbep.v.98i.249.2867

\footnotetext{
Universidade Estadual de Feira de Santana (UEFS), Feira de Santana, Bahia, Brasil. E-mail <antoniasilv@gmail.com>; $<$ http://orcid.org/0000-00026790-7761>.

II Doutora em Educação pela Universidade de São Paulo (USP), São Paulo, São Paulo, Brasil.

III Universidade Estadual de Feira de Santana (UEFS), Feira de Santana, Bahia, Brasil. E-mail: $<$ fanirehem@gmail.com>. $<$ http://orcid.org/0000-0003$2752-689 \mathrm{X}>$.

Iv Doutora em Política Social pela Universidade de Brasília (UnB), Brasília, Distrito Federal, Brasil.
}

\section{Resumo}

O artigo põe em relevo as funções políticas das associações comunitárias, buscando identificar como tais instituições têm se portado e influenciado na oferta da educação infantil e no delineamento de políticas públicas municipais para esse setor em Feira de Santana, Bahia. O estudo tomou como fontes documentos produzidos no âmbito da Secretaria Municipal de Educação do município e matérias que circularam no jornal Folha do Estado, na década de 2000. Para além do espaço local, o trabalho analisa os projetos sociais em disputa e as relações entre a sociedade política e a sociedade civil.

Palavras-chave: associações comunitárias; infância; educação infantil; política educacional. 


\section{Abstract \\ Community associations and childhood educational policies: between power struggles and performance}

This article discusses the political role performed by community associations and also identifies the usual practices of such institutions. Furthermore, it highlights the influence they have been exercising over the supplying of education for children and the outlining of local public policy for this sector in Feira de Santana, Bahia. This study was based on documents produced by the Secretaria Municipal de Educação (in Feira de Santana, Bahia) and reports from the newspaper Folha do Estado, throughout the 2000s. Beyond the local community, this paper analyzes controversial social projects and the relationship between civil and political society.

Keywords: community associations; childhood; education for children; educational policies.

Desde o final do século 20, a infância e sua educação vêm ganhando destaque social e político, seja nas discussões acadêmicas, seja nos fóruns nacionais e internacionais que influenciam as agendas, principalmente nos chamados países emergentes, entre os quais se encontra o Brasil. A busca pela universalização do direito à educação infantil, capitaneada por lutas sociais dos movimentos feministas, políticos e populares, tem colocado em pauta a sua dimensão de direito social e, ao mesmo tempo, obtido consideráveis êxitos, embora ainda haja muito a ser feito no sentido de garantir que as conquistas se efetivem.

Nesse cenário, o presente estudo põe em relevo as funções políticas das associações comunitárias, perquirindo suas escolhas e performances nos processos de constituição das políticas educacionais para a educação infantil em Feira de Santana - Bahia (BA), na década de 2000. Para tanto, analisaram-se documentos impressos produzidos no âmbito do sistema municipal de educação referentes à educação infantil, com ênfase nos relatórios da Divisão de Educação Infantil da Secretaria Municipal de Educação (SME) de Feira de Santana, além de matérias que circularam no jornal Folha do Estado, ${ }^{1}$ buscando identificar como as associações comunitárias têm se portado e influenciado na oferta da educação infantil e no delineamento de políticas públicas municipais para esse setor.

Compreendendo as associações como organismos privados de hegemonia, que dão substância ao terreno da sociedade civil, essas instituições são situadas como expressão da dialética das relações forçafraqueza que envolvem a noção de Estado integral em Gramsci (1968). Esse é definido como "[...] todo o complexo de atividades práticas e teóricas com as quais a classe dirigente justifica e mantém não só o seu domínio, mas consegue obter o consentimento ativo dos governados" (Gramsci, 1968, p. 87). Nesse sentido, o autor rompe com o conceito comum de Estado, que o restringe à condição de aparelho governamental (sociedade política), e passa a abranger os aparelhos privados de hegemonia ou sociedade civil.

\footnotetext{
Trata-se do único jornal diário em circulação no período estudado, que, portanto, registra os temas e debates em evidência no município.
} 
Nesse marco, o texto evidencia a identificação dos elementos de constituição das concepções de infância e os embates que envolvem o suposto consenso do direito à educação no Brasil, explorando as relações entre os projetos sociais em disputa e suas interfaces com as relações de força que estão dadas (frequentemente em contiguidade) entre governo e sociedade civil, para além do espaço local.

Assim, a hipótese que orienta este estudo é a de que, na arena da luta pelo direito à educação e, mais especificamente, à educação infantil, as performances das associações de moradores informam os projetos que assumem e as suas dimensões políticas como estratégias conservadorainstitucionalizadas (Gohn, 2012). A noção de performance, em diálogo com Bourdieu (1998) e Silva (2013), refere-se aqui às práticas políticas que procuram dar mais relevo aos efeitos do discurso do que à substância das ações, isto é, às práticas de espetacularização da realidade em que sobressaem as questões de pura tática política.

Combinada a essa compreensão, a noção de "relações de força" trazida por Gramsci (1968) dá pistas para serem pensados os papéis políticos potenciais e/ou reais dos organismos da sociedade civil. Percebe-se, nesse autor, a clara noção não maniqueísta das instituições, posto que as distinções que operam nas expressões de suas práticas não se vinculam meramente às escolhas pessoais, mas aos projetos políticos que representam. Em uma sociedade cindida em classes, as relações que estão dadas entre grupos dominantes e dominados, portanto, não se explicam por si, mas antes requerem a aproximação cuidadosa, incluindo a distinção dos diversos momentos constitutivos das "relações de força". Essas, embora não possam ser lidas de forma esquemática, dado que podem sofrer uma grande variedade de combinações, são caracterizadas em linhas gerais nos seguintes termos:

a) relação de força social: condições sociais e desenvolvimento das forças materiais;

b) relação de força política: grau de homogeneidade e organização dos grupos sociais. Nessas relações, estão em relevo as escolhas políticas refletidas que possibilitam a formação da unidade intelectual e moral de grupos dirigentes (ou fundamental) sobre os subordinados (Gramsci, 1968);

c) relação das forças militares: envolve as relações militares em sentido estrito, mas também a dimensão política ali implicada (Gramsci, 1968).

Para a análise proposta, destacamos a relação de força social e a relação de força política como expressões que iluminam, mais diretamente, as práticas das associações e seus efeitos nas políticas para a educação infantil. A noção de relação de força é assumida aqui, portanto, como relação constitutiva das políticas educacionais para a infância, tendo como pressuposto o fato de que as políticas públicas são pautadas, produzidas e materializadas em razão da unidade intelectual e moral que ordena as ações dos organismos da sociedade civil. 


\title{
Sociedade civil e educação para a infância: da hierarquização social à política pública
}

A organização da sociedade civil no Brasil é tratada por Dreifuss (1989) como a expressão do estado de dominação que vem prevalecendo no País, no qual sobressaem o "[...] não-desenvolvimento [sic] pleno de classes sociais populares e a não-consolidação [sic] dos segmentos sociais subordinados e subalternos como classes completas" (Dreifuss, 1989, p. 17). Nessa formulação, o autor destaca a incipiência da sociedade civil dos setores populares e o seu inverso nos setores dominantes.

As tentativas de criação de agrupamentos e partidos autênticos (autônomos) da sociedade civil-popular - por cima e além das delimitações clientelistas ou da atomização individualista - foram regularmente coibidas, de formas diversas, chegando até a proibição legal, a repressão ideológica e a coerção física. (Dreifuss, 1989, p. 18).

Essas contradições entre as organizações da sociedade civil e os papéis por elas desempenhados certamente não podem ser minimizadas quando se observam as relações de poder instituídas e os percursos das lutas sociais no Brasil, particularmente a partir do século 20. Como registra Teixeira (2008), a urbanização crescente no País, que se iniciou na década de 1940, fez surgir o movimento associativista, inicialmente centrado na questão da terra e no uso do solo, além das reivindicações por serviços públicos e equipamentos urbanos. Dentro de um amplo leque de orientações políticas, Teixeira (2008) destaca que:

\begin{abstract}
Em todo este percurso, as organizações da sociedade civil assumem vários papéis e formatos. No primeiro momento, tem [sic] um papel beneficente e assistencial, voltadas para atender necessidades dos associados, atuando na esfera privada, sem reconhecimento do Estado; posteriormente, passam a ser reguladas pelo Estado, porém de forma bem ampla, sem maiores exigências burocráticas a não ser quanto ao registro e, depois, com a certificação de utilidade pública para efeito de obter subvenção de recursos públicos. Em vários momentos estas associações são criadas com fins políticos e chegaram a desenvolver papéis de mobilização e divulgação ideológica, como aconteceu no período inicial do governo getulista, com organizações de filiação integralista (Ação Integralista Brasileira), comunista (Sociedade Amigos da Rússia), cristã-conservadora (Centro Don Vital) ou democrática (Aliança Libertadora Nacional). (Teixeira, 2008, p. 29).
\end{abstract}

Em relação à educação, a ação da sociedade civil não destoa nem quanto ao período, nem quanto à diversidade de orientações das contradições do não desenvolvimento pleno da classe popular, pelas razões já aludidas por Dreifuss (1989). Expressão disso é o próprio espaço ocupado pelo tema nas pesquisas. Em estudo sobre as lutas sociais e a educação, Campos (1991) localiza a pesquisa realizada por Celso Beisiegel, em 1964, como pioneira no Brasil. Depois dessa, só na década de 1980 outras iniciativas foram 
registradas, observando-se que, até hoje, trata-se de um tema marginal. Isso se amplia em relação às políticas de educação infantil como expressão e parte das lutas sociais brasileiras.

Nesse contexto, falar da educação infantil e de suas políticas exige observar tanto o lugar ocupado pelo tema quanto as próprias características das lutas sociais travadas no âmbito da sociedade civil brasileira. Tais lutas se relacionam à localização de seus atores e também aos interesses a partir do lugar social por eles ocupado. De partida, cabe salientar que falar de crianças como sujeitos construídos dialeticamente na e com a cultura é um fenômeno recente, embora remeta à própria história dos lugares sociais desses sujeitos e aos movimentos de constituição de um sistema de princípios fundamentais, que estabeleceu a educação como um direito universal (vide a Declaração Universal dos Direitos Humanos, de 1948, e a Declaração dos Direitos da Criança, de 1959).

Diversos estudos (Ariés, 1981; Narodowski, 2000; Heywood, 2004) reportam que, apenas no Iluminismo a infância passou a ser considerada objeto de estudo da ciência. Foi naquele contexto histórico, embasado na perspectiva de tornar o homem livre da escuridão do não saber, que a criança foi reconhecida como o pequeno adulto que, no futuro, poderia libertar-se da ignorância. Constituiu-se, nesse movimento, a necessidade da formação de um conjunto de saberes que prescrevessem, disciplinassem e padronizassem a normalidade (Sarmento, 2004). Esses padrões visavam explicar a infância pela sua naturalização e, ao mesmo tempo, negando a criança como

[...] agente na sua própria construção e na construção do mundo, mas um agente cuja ação desenvolve-se no contexto de uma práxis inelutavelmente social e histórica, que inclui tanto as sujeições e potencialidades da natureza como as ações de outros agentes. (Wartofsky, 1999, p. 89).

Procurando entender as contradições desse processo desde os aspectos etimológicos que lhe dão contorno, Lajolo (1997) ressalta que a palavra infante - infância -, em sua origem latina, "[...] recobre um campo semântico estreitamente ligado à ideia de ausência de fala" (Lajolo, 1997, p. 225, grifo da autora). A terminologia, portanto, constituída por meio dos prefixos e radicais linguísticos que compõem a palavra é a seguinte: in é um prefixo que indica negação; fante é o princípio presente do verbo latino fari, que significa falar, dizer. Em consonância com essa possível significação, a história da infância, segundo Lajolo (1997), tem sido marcada pelo silêncio.

Por não se falar, a infância não se fala, não se falando, não ocupa a primeira pessoa nos discursos que dela se ocupam. E por não ocupar esta primeira pessoa, isto é, por não dizer eu, por jamais assumir o lugar do sujeito do discurso, e, consequentemente, por consistir sempre em ele/ela nos discursos alheios, a infância é sempre definida de fora. (Lajolo, 1997, p. 226). 
Certamente, a etimologia, por si só, não explica as concepções de infância que se vêm registrando nos estudos de sociologia da infância e de políticas. Todavia, as relações implicadas entre a terminologia e as práticas sociais se fazem notar quando se observam, ao longo do tempo, os contornos que modelaram essa categoria em íntima relação com um processo de marginalização dos espaços sociais ocupados pelas crianças, principalmente nos estudos das políticas públicas. Assim, as análises que se voltaram para a desnaturalização da hierarquização social à qual a criança era e é submetida foram fundamentais para a compreensão da educação como um direito universal, cuja materialização não se desvincula de ações sistêmicas por meio de políticas específicas.

Como analisa Faleiros (2009), pode-se afirmar que as políticas pensadas e implementadas para a infância no Brasil se forjaram nas disputas entre trabalho e educação, público e privado, domínio sobre a criança e direito sobre a criança. Para o autor, as políticas devem ser analisadas com base em três eixos: a política de inserção dos pobres no trabalho precoce e subalterno; a relação entre causa pública e coisa privada; e a relação entre repressão, filantropia e cidadania.

As disputas assinaladas por Faleiros (2009) podem ser também visualizadas no trabalho de Kuhlmann Jr. (1998), quando o autor destaca três olhares que direcionaram as ações para esse segmento geracional (a infância) no Brasil: médico-higienismo, jurídico-policial e religioso.

A concepção médico-higienista é entendida, de acordo com Kuhlmann Jr. (1998), como preocupação com o saneamento e combate à mortalidade infantil - que, na década de 1870, apresentava altos índices, desfavorecendo o projeto civilizatório e moderno defendido pela ordem dominante. Por essa concepção, a infância é tratada na perspectiva da puericultura, que era considerada "a ciência da família", segundo a qual a condução do trabalho com as crianças era dada pelas mães burguesas, aliadas dos médicos no controle das condições exigidas para o papel de mãe.

A "infância moralmente abandonada" é tema da concepção jurídicopolicial sobre a assistência às crianças. Nela, segundo Kuhlmann Jr. (1998), a pobreza é segmentada como ameaçadora à ordem e à paz social das elites. A ideia do abandono moral resulta de um olhar estigmatizador sobre as famílias populares, às quais é atribuída a responsabilidade pelas condições em que vivem as crianças, sendo "os pais socialmente imprestáveis", distribuídos, conforme Kuhlmann Jr. (1998, p. 94), em três classes: "[...] os negligentes, os incapazes, que necessitam da melhoria das condições de vida (habitação etc.) e os indignos".

A religiosidade é outro fator preponderante na definição de práticas pensadas para o controle das classes trabalhadoras e, portanto, dos seus filhos, tendo a Igreja Católica como principal instituição homogeneizadora. Apesar de empregar um discurso de oposição aos excessos do liberalismo, desde a Encíclica Rerum Novarum - elaborada em 1891 pelo Papa Leão XIII - notabilizou-se pelo combate às organizações de proletários, lutando notadamente "[...] contra os sindicatos e o socialismo, vistos como irreligiosos e aproveitadores das condições do proletariado" (Kuhlmann 
Jr., 1998, p. 95). No tocante às crianças, portanto, as igrejas em geral não lograram rupturas, mantendo a tônica caritativa e de assistência à pobreza, que antes favoreceu as relações de força do capital.

Percebe-se, pois, que a preocupação com a infância é recoberta por ambiguidades, ora vinculando-a ao futuro do País, ora protegendo-a das iniquidades da pobreza e dos seus malefícios para a vida social. A ambiguidade referente ao sujeito infantil é interpretada por Rizzini (2008) como elemento desencadeador de sentimentos ambivalentes entre os adultos.

Em relação às crianças, esses sentimentos produziram atitudes que oscilaram entre salvá-las e proteger-se delas, o que remete às disputas que orientam as políticas para a infância, já sinalizadas por Faleiros (2009). Essas atitudes observadas no Brasil, contudo, não podem ser lidas, apenas, como particularidades, mas como parte de movimentos mais amplos que começaram a ser registrados nos séculos 19 e 20, tendo como uma de suas expressões o Movimento de salvação da criança, surgido nos países protestantes da Europa e nos Estados Unidos.

As reformas em prol da criança, que caracterizam o referido movimento, faziam parte de um movimento mais amplo, que visava à adaptação das instituições às demandas do sistema capitalista emergente. (...) Tratavase de uma reação diante da visível instabilidade nos negócios ao final do século XIX e das manifestações de insatisfação dos trabalhadores, que lutavam pela melhoria das condições econômicas e sociais. (Rizzini, 2008, p. 102).

O que se destaca no movimento é que ele não foi uma ação humanista a favor das classes trabalhadoras. Ao contrário, tratou-se de uma iniciativa da burguesia que buscava novas formas de controle social. Essas contradições entre patrões e trabalhadores - mais precisamente as trabalhadoras - e a pressão social exercida sobre os poderes constituídos apresentam-se aqui como elementos fundantes das políticas para a infância e, como tal, estão além dos sentimentos ambivalentes em si; porém, abrangem as tensões e as tessituras morais, que vão constituindo-se nas relações entre dominantes e dominados. As associações comunitárias são parte disso, como demonstraremos a seguir.

\section{Associações comunitárias e políticas educacionais para a infância}

A educação infantil, mesmo em um contexto de expansão recente, continua invisibilizada até em bases de dados como o Índice de Desenvolvimento Humano Municipal (IDHM), o qual registrou progressos importantes na oferta da educação em Feira de Santana, mas não trouxe dados específicos sobre a educação infantil. Segundo essa base de dados, o município foi situado na faixa alta de IDHM, com índice de 0,712 em 2010. Não obstante, no mesmo período, ainda conservava uma grande massa de crianças na faixa de 0 a 5 anos sem atendimento ou com atendimento educacional em condições controversas, como indicam os dados do Plano 
Municipal de Educação (PME) 2011-2021 (Feira de Santana, 2012). Segundo esse documento, em 2010, o município possuía uma população infantil de 0 a 5 anos de 49.700 crianças, com 33.118 na faixa etária de 0 a 3 anos e 16.582 na de 4 a 5 anos. Desse universo de crianças, menos de 1.500 tiveram acesso à creche (faixa etária de 0 a 3 anos) tanto em 2010 quanto em 2011, sendo a maior parte do acesso garantido pela rede municipal. Na pré-escola (faixa etária de 4 e 5 anos), a relação entre a população e o atendimento foi mais equilibrada, embora ainda se observe um grande contingente sem atendimento e muita proximidade entre o quantitativo de matrículas da rede municipal e da rede particular, com queda no total em 2011 e expansão do atendimento pela rede particular, como se observa na Tabela 1.

\section{Tabela 1 - Matrículas na Educação Infantil em Feira de Santana -} 2010 e 2011

\begin{tabular}{|c|c|c|c|c|c|c|}
\hline \multirow{2}{*}{$\begin{array}{c}\text { Etapa da } \\
\text { educação } \\
\text { infantil }\end{array}$} & \multirow{2}{*}{ ano } & \multicolumn{4}{|c|}{ Dependência administrativa } & \multirow{2}{*}{ Total } \\
\hline & & Federal & Estadual & Municipal & Particular & \\
\hline \multirow[t]{2}{*}{ Creche } & 2010 & - & - & 941 & 395 & 1.336 \\
\hline & 2011 & - & - & 996 & 500 & 1.496 \\
\hline \multirow[t]{2}{*}{ Pré-escola } & 2010 & - & 158 & 7.390 & 6.506 & 14.054 \\
\hline & 2011 & - & 104 & 6.044 & 7.131 & 13.279 \\
\hline
\end{tabular}

Fonte: Elaboração própria com base em dados do PME (Feira de Santana, 2012, p. 35-36).

Como é possível notar, o maior déficit no atendimento ocorria na etapa da creche, sendo o número pequeno de instituições específicas dessa natureza um fator determinante para a limitação do acesso das crianças. Essa, no entanto, não é uma realidade recente, posto que historicamente a educação infantil, e particularmente a creche, vem recebendo pouca ou nenhuma atenção dos poderes públicos no município. Segundo Brito (2015), desde a década de 1980, movimentos de bairro no município começaram a lutar por creches e a atender às crianças pequenas por meio de clubes de mães, associações de bairros e outras instituições privadas de naturezas e finalidades diversas. As creches públicas municipais surgiram na mesma década, mas de forma muito tímida, totalizando apenas quatro na gestão do prefeito José Falcão da Silva (1983-1988); entretanto, seu sucessor, Colbert Martins da Silva (1989-1992), tomou a decisão de reorientar o atendimento dessas instituições para o pré-escolar, inaugurando seis novos estabelecimentos dessa natureza ao longo do governo. Assim, as poucas creches que acolhiam as crianças em tempo integral (oito horas diárias), foram readaptadas para funcionarem em classes com turnos independentes de quatro horas de trabalho. Tal decisão, embora amparada na suposta prioridade do atendimento às crianças de 4 a 6 anos, resultou em um pacto subliminar de divisão de responsabilidades entre o governo municipal e entidades da sociedade civil na promoção do acesso à educação infantil. 
Como assinala Brito (2015):

\begin{abstract}
A manutenção das creches foi sendo reforçada pelos conveniamentos com o poder público municipal, o que foi estimulado não só porque a assistência financeira dos órgãos federais foi gradativamente tornandose escassa, mas também pelas medidas legais adotadas pelo município, como por exemplo a instituição da Lei no $1.265,18 / 06 / 1990$, que autoriza o poder público municipal a firmar convênio com entidades públicas e particulares reconhecidas como de utilidade pública para execução de obra e manutenção de serviços (...). Deste modo, o atendimento das crianças de menos de quatro anos foi, intencionalmente, retirado das instituições públicas de educação e do raio de atuação da Secretaria Municipal de Educação, e passou a ser objeto de convênios da alçada da área de assistência social. (Brito, 2015, p. 106).
\end{abstract}

Entre 1983 e 1992, portanto, a rede municipal foi equipada com cerca de dez instituições públicas de educação infantil e, desde então, esse quadro permaneceu praticamente inalterado, em relação às instituições públicas exclusivas, embora tenha se ampliado o número de classes de educação infantil em escolas de ensino fundamental e a presença de instituições conveniadas com a prefeitura. Esse último dado indica certa preferência dos governos municipais que se sucederam no período pela conservação da divisão de responsabilidades na promoção do direito à educação com as instituições privadas, notadamente as associações. Como revelam as informações oficiais trazidas no PME 2011-2021:

Conforme fontes do MEC/Inep/SEC, ano 2006, o número total de instituições por dependência administrativa está assim distribuído: na rede municipal das $154^{2}$ instituições que ofertam atendimento de educação infantil, 1,3\% (2) são creches, 6,6\% (10) pré-escolas, 21,2\% (32) associações conveniadas e 70,9\% (107) escolas de ensino fundamental com classes de educação infantil; das 7 existentes na rede estadual, $42,9 \%$ (3) são creches, $28,6 \%$ (2) pré-escolas e $28,6 \%$ (2) escolas de ensino fundamental com classes de educação infantil; enquanto que, das 190 pertencentes à rede privada, 3,7\% (7) são creches, 12,6\% (24) pré-escolas e $83,7 \%$ (159) escolas de ensino fundamental com classes de educação infantil. Nas redes estadual e privada não há registro de instituições conveniadas. (Feira de Santana, 2012, p. 37, grifos nossos).

Esses dados são reiterados no mais novo diagnóstico da educação infantil que integra o PME 2015-2024, em tramitação, com o adendo de que nesse período a rede estadual deixou de ofertar a educação infantil integralmente e está em fase final de municipalização dos anos iniciais do ensino fundamental (Feira de Santana, 2015). Assim, embora se tenha registro de que desde a década de 1980 os clubes de mães, as associações de bairros e as instituições filantrópicas e confessionais tenham atuado em favor do acesso à educação infantil, isso foi se cristalizando no município por meio de convênios em que os demandantes são também ofertantes da educação, com subsídios públicos. Não por acaso, 32 associações são conveniadas com a rede municipal.

Tais entidades, conforme prevê a Lei de Diretrizes e Bases da Educação A soma das instituiçoes
relacionadas à rede municipal totaliza apenas 151 nessa mesma citação. Nacional (LDB) - Lei no 9.394 de 20 de dezembro de 1996 -, são definidas como instituições privadas e, de acordo com o artigo 20, são classificadas 
quatro categorias, segundo as suas finalidades: particulares em sentido estrito, comunitárias, confessionais e filantrópicas (Brasil, 1996). Não obstante a definição legal, as parcerias estabelecidas muitas vezes levam a confusões sobre a identidade das instituições, se públicas ou privadas, como se faz notar no próprio texto do PME 2011-2021, citado anteriormente, quando relaciona as instituições conveniadas à rede municipal, sem distinguir as categorias de estabelecimentos credenciados pelo órgão (Feira de Santana, 2012). Essa imprecisão, se por um lado informa sobre os limites político-administrativos dos órgãos do sistema municipal, por outro traduz certa naturalização do fato de que as instituições vinculadas às associações são subvencionadas com recursos públicos, mas permanecem sob o controle privado.

Nesse cenário, a ação das associações de moradores, embora com respaldo legal, também é carregada de significados políticos, pois se, de um lado, ocupa os espaços criados pela ausência de políticas de Estado, de outro, põe em questão o próprio sentido das lutas pela educação infantil, à medida que as entidades passam a reivindicar para si a responsabilidade pela oferta direta de serviços. Ao fim e ao cabo, como registra o estudo de Campos (1991), o trabalho dessas instituições tem cumprido um importante papel na denúncia dos embargos à materialização do direito à educação.

As lutas de moradores das periferias das grandes cidades não são recentes. O percurso das mobilizações nos bairros populares de São Paulo (SP), Belo Horizonte (MG), Teresina (PI), Salvador (BA) e São Leopoldo (RS), registrados nos estudos de Campos (1991) e de Filgueiras (1994), bem como em Recife (PE), como indica Fontes (2013), permite notar a íntima relação entre a emergência das lutas populares e as necessidades que envolvem a vida nesses lugares.

Todavia, a própria organização popular trouxe, para alguns desses movimentos, a autocrítica sobre o papel das entidades e dos demandantes do direito. É o caso de algumas lideranças comunitárias de São Paulo em relação aos limites de suas reivindicações por creches quando desvinculadas de uma proposta pedagógica, além da falta de acompanhamento dos trabalhos realizados nesses espaços (Campos, 1991). Poder-se-ia agregar a essas duas questões, ainda, a ausência de exigência quanto à formação profissional das equipes que atuam na educação e no cuidado das crianças. Reconhecer a importância dessas iniciativas na falta de uma política de Estado não obsta a necessária reflexão sobre o significado de tal ausência na vida das camadas mais pobres da população.

No estudo de Campos (1991), percebe-se que a oportuna autocrítica levou alguns grupos a reverem sua atuação na luta pelo direito à educação, ressignificando as relações de força política da consciência econômicocorporativa para a consciência da solidariedade de interesse entre membros da classe social. Isso, no entanto, não é o que se observa no município de Feira de Santana, onde perdura a cisão entre educação e guarda das crianças, haja vista a própria dificuldade em dissociar as instituições conveniadas que mantêm atendimento educacional dos vínculos históricos com assistência social, conforme indicado por Brito (2015) e observado nos documentos analisados, os quais comentaremos mais detidamente a seguir. 
Portanto, diferentemente dos movimentos de autocrítica operados nas grandes cidades referidas por Campos (1991), entre outros, nota-se que em Feira de Santana as associações buscam manter-se como protagonistas da oferta da educação. Acompanhando tanto os relatórios da Divisão de Educação Infantil da Secretaria de Educação do município quanto as notícias que circularam na cidade pelo Jornal Folha do Estado, percebe-se que a luta pelo atendimento às crianças em instituições públicas esteve fora de órbita durante a década de 2000. Assim, as poucas aparições do tema da educação infantil nesse jornal revelam que o foco das atenções recaiu sobre as solicitações específicas relativas ao funcionamento das instituições, sem problematizar a presença delas e a relação com o poder municipal.

Entre as escassas matérias que circularam no jornal analisado que tratam da educação infantil, uma, especialmente, exemplifica bem essa situação: Educação infantil ampliada. A matéria se refere a convênios da prefeitura de Feira de Santana com associações de bairros e filantrópicas, num total de 30, que "sediam escolas na área de educação infantil" (Educação..., 2002, p. 3). Afirma que todas as entidades beneficiadas oferecem um atendimento adequado na área de educação infantil, que são fiscalizadas e acompanhadas pela SEC, acolhendo e naturalizando a atuação das instituições. Isso também é observado em outras matérias que, em lugar da problematização da oferta da educação infantil pelos poderes públicos, registram reivindicações das entidades conveniadas por repasses de recursos para pagamento de água, luz e aluguel, compra de material escolar e merenda e outros custeios, bem como por cessão de profissionais. Assim, sem a problematização da própria existência de instituições conveniadas de educação, vão sendo mantidos os espaços para algumas demandas inusitadas, como "[...] manutenção financeira para pagamento dos professores e funcionários para atenuar os efeitos da inadimplência" (Feira de Santana, 2003, s. p., grifos nossos).

A matéria Moradores colaboram com a creche tia Bebétambém ilustra esse fato quando informa que a diretora da creche criou um bazar visando a estabelecer o hábito de colaboração dos moradores com a instituição, que atende a 120 crianças: "Vamos tentar fazê-lo todo final de mês para entrar no calendário, eles que colaboram com a creche que, afinal de contas, atende seus filhos" (Moradores..., 2005, p. 4).

Olhando para os relatórios produzidos pelos próprios técnicos da SME ao longo da década (Feira de Santana, 2001a, 2001b, 2003, 2004, 2005, 2006, 2008), pode-se não só identificar como as instituições conveniadas são percebidas por eles, mas também caracterizar as condições de funcionamento e atendimento da educação infantil. O Relatório sobre as Associações do Município de Feira de Santana - BA, de 2001, registra essa situação de forma explícita em um trecho que define as condições de funcionamento como extremamente precárias. Em continuidade a essa avaliação, expõe o relatório:

Vale ressaltar que não existe nenhuma creche municipal e que as préescolas existentes são insuficientes para atender a demanda, uma vez que há mais de dez anos não é construída uma instituição de educação infantil em Feira de Santana, o que estimula o aparecimento das associações. (Feira de Santana, 2001a, s.p.). 
Nos anos seguintes, os relatórios confirmam a manutenção desse cenário. A despeito disso, o Memorial da Gestão da Educação Municipal 2004/2008 informa, em relação ao desenvolvimento da educação básica, que a diminuição dos convênios com as instituições de educação infantil era uma meta. Não obstante, o que a secretaria logrou foi apenas o acompanhamento dos convênios de creches e a definição de um cardápio, supostamente, mais saudável (Feira de Santana, 2008). Não constam ali dados sobre o quantitativo de instituições conveniadas no período, embora o PME 2011-2021 se refira a um contingente de 32 associações atuando em convênio com o município (Feira de Santana, 2012).

Pode-se depreender desses dados, bem como do conjunto de informações dos 28 relatórios da Secretaria Municipal de Educação sobre a ação das associações, que a educação infantil em Feira de Santana tem sido ofertada de forma ampla por instituições não governamentais e que a relação desses setores com um projeto educacional tem sido problematizada apenas conjunturalmente e sem efeitos políticos na agenda municipal.

Com base na análise desse material, percebe-se que boa parte das instituições funciona em condições não satisfatórias, conforme consta na Tabela 2. Ademais, algumas delas ainda mantêm algum tipo de cobrança à população atendida.

Tabela 2 - Avaliação das Áreas e Condições de Funcionamento das Escolas de Associações do Município de Feira de Santana - 2001

\begin{tabular}{c|c|c|c|c|c|c|}
\hline & \multicolumn{7}{|c|}{ Espaços físicos } \\
\hline $\begin{array}{c}\text { Áreas/ } \\
\text { condiçóes/ } \\
\text { existência }\end{array}$ & Salas & Banheiro & Mobiliário & Secretaria & $\begin{array}{c}\text { Área para } \\
\text { recreação }\end{array}$ & Cozinha \\
\hline Muito Boa & - & - & - & - & - & 1 \\
\hline Péssima & - & - & - & - & - & 1 \\
\hline Adequado & - & 5 & 15 & - & - & 1 \\
\hline Inadequado & & 18 & 10 & - & - & - \\
\hline Satisfatório & 16 & 1 & - & - & 4 & 13 \\
\hline Insatisfatório & 8 & - & - & - & 3 & 5 \\
\hline Razoável & 1 & - & - & - & - & - \\
\hline Sim & - & - & - & 21 & 10 & 1 \\
\hline Não & - & - & - & 4 & 8 & 3 \\
\hline Não & 14 & - & - & - & - & - \\
\hline
\end{tabular}

Fonte: Elaboração própria com base em dados do Relatório sobre as Associações do Município de Feira de Santana (Feira de Santana, 2001a). 
Além das condições de funcionamento das escolas e associações, outras informações presentes nos relatórios (Feira de Santana, 2001a, 2001b, 2002, 2005) avaliados dão pistas do cenário da educação infantil oferecida por essas instituições:

a) ofertam creches e pré-escolas;

b) recebem merenda escolar, corpo docente e material da secretaria de educação;

c) quase $100 \%$ se localizam na periferia da cidade;

d) aproximadamente $80 \%$ funcionam em construções com estrutura residencial, sem espaço para o desenvolvimento de atividades educativas e socializadoras;

e) possuem muitas salas pequenas para acomodar um número excessivo de crianças, em mobiliário inadequado, com iluminação e ventilação deficientes;

f) mais de $85 \%$ não possuem banheiros adequados para o uso de crianças pequenas.

Assim, além das condições precárias de funcionamento das instituições, da baixa qualidade e da desarticulação pedagógica, sobressai também, como aspecto contraditório, o fato de que a demanda é apresentada pelos ofertantes, isto é, pelas próprias organizações. Nessa dinâmica, há vários elementos contidos, pois entidades de movimentos sociais que emergiram em nome da luta pelos direitos se converteram em ofertantes diretos da educação. Aliada a essa presença controversa das associações, percebe-se que, no período estudado, nenhuma iniciativa sistêmica do governo municipal para o delineamento de uma política pública de educação infantil foi realizada. A não política, ou a sua definição pela ausência, indica que o tom para as ações no setor vem sendo dado pelas práticas de filantropia, tendo como fundamento o benefício das crianças necessitadas, bem ao modo das feições ambivalentes das abordagens mencionadas em diálogo com Kuhlmann Jr. (1998) e Rizzini (2008).

Nesse percurso, as associações colocaram-se diretamente como executoras da educação infantil, acentuando a distorção entre causa pública e coisa privada. Como já se buscou assinalar, as organizações da sociedade civil assumiram no Brasil papéis e formatos diferenciados (Teixeira, 2008). No cenário dos últimos 20 anos, isso se evidenciou ainda mais em virtude das configurações políticas que passaram a ordenar as funções dos governos.

Nesse cenário, a ideia da inoperância do Estado, disseminada como justificativa para as reformas administrativas desencadeadas e as suas formas de expressão, acentuou como alternativa a descentralização das responsabilidades governamentais no provimento de políticas sociais e, simultaneamente, o papel das organizações sociais (OS) em atividades complementares à ação do Estado.

Vinculado aos princípios da reforma administrativa defendida por Bresser Pereira (1996), o conceito refere-se à triangulação de tipos de propriedade que, na visão do autor, potencializam a administração das atividades na vida social contemporânea: estatal, pública não estatal e privada. Nessa forma de organização das responsabilidades sociais, 
flexionou-se a dicotomia entre o estatal e o privado, transferindo às organizações sociais a gestão de serviços (Silva, 2007).

Essa contradição alcança o atendimento às crianças pequenas antes mesmo das formulações de Bresser Pereira (1996), posto que a atuação de entidades privadas, sem fins lucrativos e subsidiadas com recursos públicos não é recente no município, mas, ao que indica, foi evidenciada nas últimas duas décadas e se fortaleceu com o desenvolvimento do conceito de descentralização das responsabilidades. As razões para isso, além do alinhamento aos princípios da reforma administrativa, podem ser encontradas, também, no crescente esvaziamento das lutas sociais populares nascidas de baixo e orientadas pela resistência ao projeto hegemônico.

Os movimentos entre o direito reivindicado e o direito protegido situam-se como espaços temporais e sociais de organização e disputas, que fazem germinar as próprias políticas públicas enquanto processos de concepção, ordenamento e implementação de ações demandadas pelas forças políticas em suas dinâmicas de acomodação/administração dos conflitos inerentes ao Estado capitalista. Para além do aparato governamental, a sociedade civil organizada, em suas múltiplas clivagens, não pode ser vista apenas como mensageira de projetos de interesses coletivos, mas, principalmente, como agente político, que pode operar tanto na manutenção do status quo quanto no seu combate. Nesse aspecto, as políticas para a educação na e da infância não apenas se vinculam à positivação do direito à educação, pois, sendo parte do jogo no qual forças e consensos são confrontados, também fazem eclodir fluxos contraditórios - e frequentemente descontínuos - nos seus processos de constituição.

Como bem registrou Dreifuss (1989), no Brasil, a separação de sociedade civil e sociedade política consubstanciou-se mediante a luta das elites e da classe dominante emergente para assegurar o contínuo realinhamento conservador, calcado no sistemático desarranjo da sociedade civil-popular. Não por acaso muitos aparelhos privados de hegemonia se revestem do papel de aparentes defensores dos interesses coletivos, porém, prestam-se ao papel de reproduzir relações de dominação. Portanto, quando falam em nome da coletividade o fazem mais como uma performance teatral do que como expressão dos reais interesses que representam.

Embora a inclusão das crianças resguarde uma dimensão social da promoção da igualdade de condições, também encerra aspectos performáticos que encobrem os interesses burocráticos e políticos daqueles que, em nome do direito à educação, têm encoberto as tensões e os conflitos que envolvem a luta pela sua materialização como dever do Estado. Assim, ainda que reconheçamos o papel desempenhado pelas associações ao denunciarem, por meio de suas presenças, as relações controversas do Estado na garantia do direito à educação infantil, chamamos atenção para o uso dessas instituições por agentes que falam em nome dos interesses coletivos, mas têm servido de instrumento de formação de consenso em torno da idealização das ações da sociedade civil, ao passo que se esvazia a responsabilização dos governos na promoção da educação pública para todos. 


\section{Considerações finais}

As associações comunitárias no município em tela têm se mostrado frágeis como vetores de mudança das correlações de forças dominantes. Em lugar de uma ameaça real às práticas econômico-corporativas, elas têm servido de instrumento para a subsunção aos projetos dominantes. A subsunção, em sua dupla dimensão de subordinação-inclusão, revela-se pela prática de inclusão das crianças em condições precárias que, muitas vezes, reproduzem o lugar social ocupado pelos seus destinatários. Nesse contexto é que as associações têm operado mais como agentes de legitimação do que de resistência e proposição de um projeto de classe que confronte a lógica dominante.

Ao se colocarem como responsáveis diretas pela execução das atividades educativas, como indicam alguns documentos, essas entidades acabaram por sombrear o seu papel de pressionar pela oferta da educação pública estatal, mas, antes, têm contribuído para a precarização da educação mediante a manutenção de instituições em condições operacionais aquém dos requisitos pedagógicos e de infraestrutura já regulamentados no País.

Por fim, cabe lembrar que a nova redação dada ao artigo $4^{\circ}$ da LDB tornou obrigatória a educação de 4 a 17 anos de idade e reafirmou o direito à educação infantil gratuita. Como na redação anterior, o artigo $5^{\circ}$ preconiza que a educação básica obrigatória é direito público subjetivo, "[...] podendo qualquer cidadão, grupo de cidadãos, associação comunitária, organização sindical, entidade de classe ou outra legalmente constituída e, ainda o Ministério Público, acionar o poder público para exigi-lo" (Brasil, 1996). Isso não só significa a ampliação da obrigatoriedade da educação para uma faixa das crianças da educação infantil, mas traz, para a ordem do dia, o acento da emergência da luta por políticas públicas em bases comprometidas com a indissociação da relação educação-cuidado na/para a infância, tendo em vista a superação das relações de força dominantes.

\section{Referências bibliográficas}

ARIES, P. História social da criança e da família. 2. ed. Rio de Janeiro: Guanabara, 1981.

ATLAS DO DESENVOLVIMENTO HUMANO NO BRASIL. Perfil Municipal. 2013. Disponível em: <http://atlasbrasil.org.br/2013/perfil/ feira-de-santana_ba $>$. Acesso em: 12 set. 2013.

BOURDIEU, P. Contrafogos: táticas para enfrentar a invasão neoliberal. Rio de Janeiro: Jorge Zahar, 1998.

BRASIL. Lei n ${ }^{\circ}$ 9.394, de 20 de dezembro de 1996. Estabelece as diretrizes e bases da educação nacional. Diário Oficial da União, Brasília, 23 dez. 1996. 
BRASIL. Ministério da Educação (MEC). Subsídios para credenciamento e funcionamento de instituições de educação infantil. Brasília: MEC/SEF, 1998. Disponível em: <http://portal.mec.gov.br/seb/arquivos/pdf/scfiei. pdf $>$. Acesso em: 10 ago. 2012.

BRESSER PEREIRA, L. C. Crise econômica e reforma do Estado no Brasil: para uma nova interpretação da América Latina. São Paulo: Editora 34, 1996.

BRITO, C. F. Transição política e educação infantil em Feira de Santana: a democratização e seus sentidos no governo Colbert Martins (19891992). 2015. 159 f. Dissertação (Mestrado em Educação) - Programa de Pós-Graduação em Educação, Universidade Estadual de Feira de Santana, Feira de Santana, 2015.

CAMPOS, M. M. As lutas sociais e a educação. Cadernos de Pesquisa, São Paulo, n. 59, p. 56-64, nov. 1991.

DREIFUSS, R. O jogo da direita. 2. ed. Petrópolis: Vozes, 1989.

EDUCAÇÃO infantil ampliada. Jornal Folha do Estado da Bahia, Feira de Santana, p. 3, 24 abr. 2002.

FALEIROS, V. P. Infância e processo político no Brasil. In: RIZZINI, I.; PILOTTI, F. (Org.). A arte de governar crianças: a história das políticas sociais, da legislação e da assistência à infância no Brasil. 2. ed. São Paulo: Cortez, 2009. p. 33-96.

FEIRA DE SANTANA (BA). Governo Municipal. Documentos aprovados em Plenária Final do PME: textos por salas temáticas. Disponível em: $<$ http://www.feiradesantana.ba.gov.br/conferenciadeeducacao/doc1. asp >. Acesso em: 30 maio. 2016.

FEIRA DE SANTANA (BA). Secretaria Municipal de Educação (SME). Relatório sobre as associações do município de Feira de Santana. Feira de Santana, 2001a. Mimeografado.

FEIRA DE SANTANA (BA). Secretaria Municipal de Educação (SME). Divisão de Educação Infantil (DEI). Relatório - 2001. Feira de Santana, 2001b.

FEIRA DE SANTANA (BA). Secretaria Municipal de Educação (SME). Divisão de Educação Infantil (DEI). Relatório das atividades desenvolvidas pela divisão de Educação Infantil. Feira de Santana, 2002.

FEIRA DE SANTANA (BA). Secretaria Municipal de Educação (SME). Divisão de Educação Infantil (DEI). Relatório das ações desenvolvidas no ano de 2003. Feira de Santana, 2003.

FEIRA DE SANTANA (BA). Secretaria Municipal de Educação (SME). Divisão de Educação Infantil (DEI). Relatório das ações desenvolvidas no ano de 2004. Feira de Santana, 2004. 
FEIRA DE SANTANA (BA). Secretaria Municipal de Educação (SME). Divisão de Educação Infantil (DEI). Relatório das ações desenvolvidas em 2005. Feira de Santana, 2005.

FEIRA DE SANTANA (BA). Secretaria Municipal de Educação (SME). Departamento de Ensino. Plano de Trabalho/2006. Feira de Santana, 2006.

FEIRA DE SANTANA (BA). Secretaria Municipal de Educação (SME). Memorial da gestão da Educação Municipal 2004/2008. Feira de Santana, dez. 2008. Mimeografado.

FEIRA DE SANTANA (BA). Governo Municipal. Lei 3.326, de 5 de junho de 2012. Aprova Plano Municipal de Educação e dá outras providênciasPME 2011-2021. Feira de Santana, 2012. Disponível em: <http://www. feiradesantana.ba.gov.br/seduc/arq/Plano_educa.pdf $>$. Acesso em: 9 mar. 2014.

FEIRA DE SANTANA (BA). Governo Municipal. Plano Municipal de Educação 2015-2025. Feira de Santana, 2015. Versão aprovada pela Conferência Municipal de Educação.

FILGUEIRAS, C. A. C. A creche comunitária na nebulosa da pobreza. Cadernos de Pesquisa, São Paulo, n. 88, p. 18-29, fev. 1994.

FONTES, B. A. S. A estrutura organizacional das associações políticas voluntárias: um estudo de caso das associações de moradores no Recife. In: ENCONTRO NACIONAL DA ASSOCIAÇÃO NACIONAL DE PÓS-GRADUAÇÃO E PESQUISA EM PLANEJAMENTO URBANO E REGIONAL, 15., 2013, Recife. Anais... Recife: ANPUR, 2013. p. 979- 1007.

GOHN, M. G. Movimentos sociais e educação. 8. ed. São Paulo: Cortez, 2012.

GRAMSCI, A. Maquiavel, a política e o Estado moderno. Rio de Janeiro: Civilização Brasileira, 1968.

HEYWOOD, C. Uma história da infância: da idade média à época contemporânea no ocidente. Porto Alegre: Artmed, 2004.

IANNI, O. Construção de categorias. São Paulo, 1986. Transcrição de aula dada no curso de Pós-Graduação em Ciências Sociais da PUC/SP.

KUHLMANN JR., M. Infância e educação infantil: uma abordagem histórica. 2.ed. Porto Alegre: Mediação, 1998.

LAJOLO, M. Infância de papel e tinta. In: FREITAS, M. C. História social da infância no Brasil. 2. ed. São Paulo: Cortez, 1997. p. 225-246.

MORADORES colaboram com a creche tia Bebé. Jornal Folha do Estado da Bahia, Feira de Santana, p. 4, 6 set. 2005. 
NARODOWSKI, M. Adeus à infância (e à escola que educava) In: SILVA, L. H. A escola cidadã no contexto da globalização. 4. ed. Petrópolis:

Vozes, 2000. p.172-177.

ORGANIZAÇÃO DAS NAÇÕES UNIDAS (ONU). Declaração Universal dos Direitos Humanos: adotada e proclamada pela resolução 217 A (III) da Assembléia Geral das Nações Unidas em 10 de dezembro de 1948. Brasília: Unesco, 1998. Disponível em: <http://unesdoc.unesco.org/ images/0013/001394/139423por.pdf $>$.

ORGANIZAÇÃO DAS NAÇÕES UNIDAS (ONU). Declaração Universal dos Direitos das Crianças. Disponível em:<http://www.dhnet.org.br/direitos/ sip/onu/c_a/lex41.htm>.

REHEM, F. Q. N. "Coisa de pobre": a política de educação infantil em Feira de Santana (2001-2008). 2013. 241 f. Tese (Doutorado em Política Social) - Departamento de Serviço Social, Universidade de Brasília, Brasília. 2013.

RIZZINI, I. O século perdido: raízes históricas das políticas públicas para a infância no Brasil. 2. ed. São Paulo: Cortez, 2008.

SARMENTO, M. J. As culturas da infância nas encruzilhadas da segunda modernidade. In: CERISARA, A. B.; SARMENTO, M. J. (Org.). Crianças e miúdos: perspectivas sociopedagógicas da infância e da educação. Porto: Asa Editores, 2004. p. 9-34.

SILVA, A. A. As políticas públicas para a educação básica na Bahia nos anos 90: propostas e ações nas gestões de Antônio Carlos Magalhães e Paulo Souto (1991-1998). 2007. 243 f. Tese (Doutorado em Educação) Universidade de São Paulo, São Paulo. 2007.

SILVA, A. A. Ensino fundamental de nove anos: ordenamento e contradições em escolas públicas e privadas na Bahia. Revista Brasileira de Política e Administração da Educação, Goiânia, v. 29, n. 3, p. 427-444, set./dez. 2013.

TEIXEIRA, E. C. Organizações da sociedade civil e poder público. In: TEIXEIRA, E. C. (Coord.). Sociedade civil na Bahia: papel político das organizações. Salvador: Ed. da UFBA, 2008. p. 21-35.

WARTOFSKY, M. A construção do mundo da criança e a construção da criança do mundo. In: KOHAN, W. O; KENNEDY, D. (Org.). Filosofia e infância: possibilidades de um encontro. Petrópolis: Vozes, 1999. p. 89-128.

Recebido em 2 de agosto de 2016.

Solicitação de correções em 6 de novembro de 2016.

Aprovado em 30 de março de 2017. 